\title{
COVID-19 Pandemic Preparedness and Response of Chronic Disease Patients in Public Health
} Facilities

This article was published in the following Dove Press journal: International Journal of General Medicine

Tinsae Abeya Geleta' Berhanu Senbeta Deriba (D) Rebik Shukure Beyane (D) Ahmed Mohammed' Tadesse Birhanu ${ }^{2}$ Kemal Jemal $\mathbb{D i D}^{3}$

'Salale University, College of Health Sciences, Department of Public Health, Fitche, Ethiopia; ${ }^{2}$ Salale University, College of Agricultural and Natural Resources, Department of Animal Sciences (Infectious Diseases), Fitche, Ethiopia; ${ }^{3}$ Salale University, College of Health Sciences, Department of Nursing, Fitche, Ethiopia
Correspondence: Kemal Jemal Email kemal_jemal@slu.edu.et
Background: The Coronavirus Diseases 2019 (COVID-19) causes a unique threat and a great challenge to chronic disease patients. Apart from its severity for all communities, a chronic disease patient is highly vulnerable to the current COVID-19 pandemic. Therefore, this study aimed to assess preparedness and response against the COVID-19 among chronic diseases patients who had follow-up at healthcare facilities.

Methods: An institutional-based cross-sectional study was conducted in the North Shoa Zone from May 5, 2020, to June 5/2020. A pre-tested and semi-structured questionnaire was used to collect data. The study participants were selected by simple random sampling technique. The data were entered into the Epi-data and exported to SPSS for cleaning and analysis. Bivariable and multivariable logistic regressions were used to identify the factors associated with the COVID-19 preparedness and response.

Results: A total of 410 (97\%) patients were responded to face to face interview administered questionnaire. Nearly two-thirds of the respondents had good knowledge, 54\% were well prepared, and $63 \%$ had a good response to the COVID-19 pandemic. Male participants, news media (TV \& Radio), social media, tuberculosis, hypertension, and diabetes mellitus were significantly associated with a good preparedness. Informal education, news media (TV \& Radio), and having hypertension were significantly associated with good response to the COVID-19 pandemic.

Conclusion: The prevalence of preparedness and response to the COVID-19 pandemic among chronic disease patients was low. Male participants, source of information, educational status, and having chronic diseases were significantly associated with the COVID-19 prevention preparedness and response. It should be continued to provide awareness creation for chronic patients through news media (TV and radio) and social media to increasing the preparedness and response to the COVID-19 pandemic.

Keywords: COVID-19, preparedness, response, chronic patients, Ethiopia

\section{Background}

A COVID-19 pandemic is a group of viruses belonging to the family of Coronaviridae, which infects both humans and animals. ${ }^{1}$ Human coronavirus can cause a mild illness similar to a common cold. In contrast, others cause more severe diseases such as MERS (Middle East Respiratory Syndrome) and SARS (Severe Acute Respiratory Syndrome). ${ }^{2}$ The current COVID-19 starting from Wuhan city on December 31, 2019, spread too many other countries. ${ }^{3}$ Since May 05, 2020, more than $3,517,345$ infected cases with 243,401 confirmed deaths were reported 
globally. In America, a total of 1,477,447 infected cases and 79,590 deaths have been reported. In Europe, a total of $1,566,684$ infected cases with 145,602 confirmed deaths. In Africa, 32,570 infected cases and 1,112 deaths have been reported, whereas in Ethiopia, 665 infected cases with 22 deaths. ${ }^{4}$

The most common clinical features of the COVID-19 are fever, tiredness, and dry cough. Some patients may have aches and pains, nasal congestion, runny nose, sore throat, or diarrhea. In more severe cases, the infection can cause pneumonia, severe acute respiratory syndrome, and sometimes death. $^{5}$

The COVID-19 infected all age groups, presenting $80 \%$ of patients who had developed mild to moderate symptoms or including non-pneumonia and pneumonia cases, $13.8 \%$ have severe symptoms, and $6.1 \%$ are critical or respiratory failure, septic shock, and/or multiple organ dysfunctions. ${ }^{6}$ About $2.4 \%$ of the total reported cases were an individual's under-19 years old, and a very small proportion of those aged have developed severe $(2.5 \%)$ or critical symptoms $(0.2 \%)$. The severity of the virus is more common in the aged population. ${ }^{7}$

The World Health Organization (WHO) defines noncommunicable diseases (NCDs) is as chronic conditions that do not result from an acute infectious process and hence are not communicable with a longer duration, which a complete cure is rarely achieved and are the result of a combination of genetic, physiological, environmental and behavioral factors. ${ }^{8}$ These noncommunicable disease includes cardiovascular disease, cancer, diabetes mellitus, chronic respiratory disease, chronic neurological disorders, musculoskeletal diseases, and other non-infectious conditions. ${ }^{9,10}$

According to different reports, the COVID-19 is more severe among chronic disease patients. A meta-analysis study addressing the prevalence of chronic disease patients infected with COVID-19 indicated that hypertension, diabetes, respiratory system disease, cardiovascular disease, and other chronic disease patients were more susceptible to the COVID-19. ${ }^{11}$ Other studies found that hypertension and diabetes mellitus is the most common chronic disease which infected by COVID-19 pandemic and has high records of deaths. ${ }^{10,12}$

Preparedness and response of the COVID-19 are crucial for minimizing the risk of infection and transmission through community and health-care facilities. However, evidence-based evaluations of chronic disease patients targeted to preparedness and responses of the COVID-19 are rare in the low resourced countries, particularly in Ethiopia. Therefore, this study aimed to determine the preparedness and response to the COVID-19 among chronic diseases patients who had follow-up at healthcare facilities. Again, this study's results are important to develop appropriate and rapid intervention among chronic disease patients in the North Shoa Zone of Oromiya regional state.

\section{Methods}

\section{Study Design, Period, and Setting}

An institutional-based cross-sectional study was conducted from May 5, 2020, to June 5/2020 in North Shoa Zone healthcare facilities. The North Shoa Zone has 13 woredas and two town administration with a total area of 10,322.48 $\mathrm{Km}$ square. It has 369 public health facilities in the catchment area (two general hospitals, three primary hospitals, 65 health centers, and 297 health posts). The healthcare facilities provide for more than 1.6 million populations in the North Shoa Zone of Oromiya region.

\section{Source and Study Population}

The source populations were all chronic disease patients who had follow-up at North Shoa healthcare facilities in the North Shoa Zone. Those chronic disease patients who had follow-up at selected healthcare facilities were the study population.

\section{Inclusion and Exclusion Criteria}

All patients whose ages greater than 15 years and who have chronic disease (cardiovascular disease, cancer, diabetes mellitus, chronic respiratory disease, tuberculosis, and HIV/AIDS) follow-up at the selected health facilities for more than six months were included. In contrast, chronic disease patients who were severely ill were excluded from this study.

\section{Sample Size and Sampling Procedure}

The single population proportion formula was used to come up for the final sample size with the following assumption. Due to a lack of published data, we considered a proportion of $50 \%(0.5)$ and a $5 \%(0.05)$ margin of error with a $95 \%$ level of confidence interval (two-sided alpha $=0.05$ ). After considering a $10 \%$ non-response rate, the final sample size was 423 . The study was conducted in three hospitals and four health centers. We selected these healthcare facilities purposely because they have a high number of patients with 
chronic diseases. The number of study participants allocated proportionally to each healthcare facility based on the number of patients attended each hospital and health center for one month obtained from chronic disease patients department registration books (Figure 1). The first participant was selected by lottery method.

\section{Data Collection Instruments and Techniques}

A pre-tested and semi-structured questionnaire was adapted by reviewing different literature. ${ }^{13,14}$ The questionnaire was initially prepared in the English language, translated to Afan Oromo and Amharic, and then backtranslated to the English by language experts to check its consistency. The questionnaire consisted of sociodemographic and economic characteristics, knowledge, preparedness, and response to the COVID-19 pandemic.

The data were collected by seven BSC public health officers through face to face interviews and supervised by four MPH public health experts. Before the actual data collection process, the data collectors and supervisors were trained for three days about the study's aim and purpose, disclosing and ethical aspects of the study, and data collection technique.

The data collection instruments were pre-tested at Shano hospital among a sample of $21(5 \%)$ chronic patients. The questionnaire was checked for completeness and its inconsistency by the supervisor. Accordingly, after discussion with data collectors and supervisors, a necessary measure was taken, and modification was done before actual data collection. We collected data from noncommunicable chronic diseases such as cardiovascular disease, cancer, diabetes mellitus, chronic respiratory disease, and other communicable chronic diseases like tuberculosis and HIV/AIDS.

The knowledge, preparedness, and response were measured using 12, 11, and 16 questions, respectively. The outcomes were calculated, taking the mean scores as a cut-off point after testing each outcome's results' normality distribution. The scores greater than the mean score were considered a good preparedness, knowledgeable, and good response, whereas below the mean scores were considered a poor preparedness, not knowledgeable, and poor responses to the COVID-19. The questionnaires' reliability was checked

\section{From five hospitals and 65 health centers in North Shoa Zone}

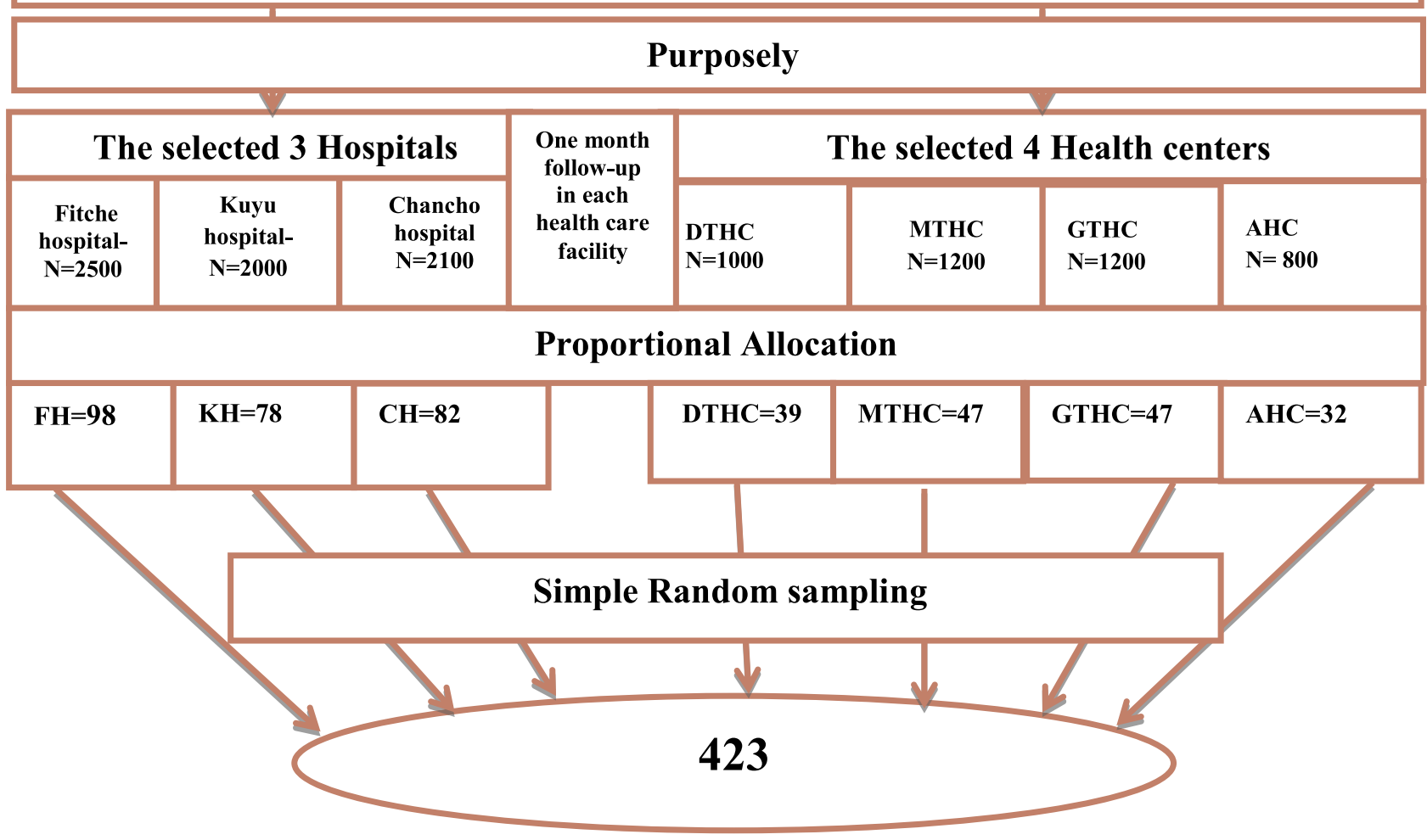

Figure I Schematic presentation of sample size allocation in the North Shoa Zone healthcare facilities, Oromia region, Ethiopia. 
with Cronbach's alpha 0.873 for knowledge, 0.781 for responses 0.752 for preparedness.

\section{Data Processing and Analysis}

After data collection, each questionnaire was checked for completeness and consistency of the respondent's information. The collected data was entered into the Epi-data manager version 4.4.1 to minimize errors. Then the data were exported to SPSS version 23 for cleaning, editing, and analysis. The data were checked for missed values. Descriptive analysis, like frequencies, percentages, means, and standard deviation, tables, and graphs were used to present the results. Bivariable and multivariate logistic regressions were used to identify the factors associated with preparedness and response towards COVID-19 prevention. Variables with P-value $\leq 0.2$ in the bivariable analysis were included in a multivariable logistic regression analysis to control the confounding effect variables. Statistical significance was declared at $\mathrm{P}$-value $<0.05$. The test's model goodness was checked by Hosmer-Lemeshow goodness fit, and the p-value for the model fitness test was 0.935 and 0.786 for preparedness and responses, respectively.

\section{Ethical Consideration}

This study was conducted in accordance with the Declaration of Helsinki. The Salale University Ethical Review Committee approved the ethical clearance of written consent for above 18 years of age and assent form for under 18 years of age from parents/guardians on April 27/2020 with Ref. No. SLUERC/ 035/2020. A support letter was obtained from the North Showa Zone health bureau, and official permission was obtained from the selected hospitals and health centers. Written consent was obtained from the study participants whose age $\geq 18$ years, and assent was obtained from parents/guardians for 15 to 18 years old to confirm the participation after explaining the study's objective. Study participants' privacy and confidentiality were maintained by excluding their names from the questionnaire and keeping their data in a password locked computer.

\section{Results}

\section{Socio-Demographic and Economic Characteristics of Respondents}

In this study, 410 chronic disease patients participated with a response rate of $97 \%$. The participants' majorities were male $215(52.4 \%)$ and aged more than or equal to 45 years old $175(42.6 \%)$. Greater than half of the respondents resided in rural areas (50.7\%). More than half 212 $(51.7 \%)$ of participants were not attending formal education. More than two-third of the respondents were married 295 (72.0\%). Nearly two-thirds of the study participants were unemployed and earned less than or equal to 2000 Ethiopian Birr monthly income (Table 1).

\section{Source of Information}

Regarding sources of information, participants heard about the COVID-19 pandemic for the first time from news media (TV and Radio) (36.8\%) followed by social media/ internet (23.4\%) and health-care providers (18.5\%) (Figure 2 ). The majority of the respondents trusted news media (TV and Radio) (32.7\%), health-care providers (33.7\%), family, and friends (16.8\%) (Figure 3).

\section{Knowledge Toward COVID-19}

In this study, the mean knowledge score for the study participants with standard deviation was $12.11 \pm 2.7$. Nearly twothirds of the respondents had a piece of good knowledge about COVID-19. Most of the study participants heard about COVID-19 (96.4\%), know the transmission of the disease (89.8\%), and mode of transmission (50.2\%). More than twothirds of the study respondents knew the disease's main signs and symptoms. Around $51 \%$ of respondents knew the virus did not have the medication. Conversely, the majority of the respondents knew the main COVID-19 prevention method like; wearing masks and gloves $366(89.3 \%)$, rubbing hands with alcohol and sanitizer 328 (80.0\%), washing hands with soap and water 354 (86.4\%), social distance 350 (85.4\%) and physical distance 354 (86.3\%). More than two-thirds of the study participants knew that the most at-risk populations were chronic diseases (78.8\%) and elder person (75.6\%). From chronic disease patients who had a follow-up, $72 \%$ of the study respondents knew how to protect themselves from the virus (Table 2).

\section{Preparedness Towards COVID-19 Prevention}

In this survey, we found the mean score and standard deviation of the study participants for preparedness were $6.63 \pm 2.9$. Fifty-four percent of respondents were well prepared to prevent the COVID-19 pandemic. The majority of the respondents were stocked alcohol or sanitizer $(72.9 \%)$, frequently reduces hospital visiting (64.6\%), and posted an emergency phone number at home (35.4\%). Two hundred sixty-one $(63.7 \%)$ of the study participant's medication were refilled every three months. Around $53 \%$ of the study participants had stocked sufficient amounts of food to reduce the vesting 
Table I Socio-Demographic Characteristics of Study Participants Who Had Follow-Up in the North Shaw Zone Healthcare Facilities, Oromia Region, from May 5, 2020, to June $5 / 2020(n=410)$

\begin{tabular}{|c|c|c|}
\hline Variables & $\begin{array}{l}\text { Number of } \\
\text { Participants }\end{array}$ & $\begin{array}{l}\text { Percent } \\
\text { (\%) }\end{array}$ \\
\hline \multicolumn{3}{|l|}{ Sex } \\
\hline Male & 215 & 52.4 \\
\hline Female & 195 & 47.6 \\
\hline \multicolumn{3}{|l|}{ Age } \\
\hline $15-24$ & 36 & 8.8 \\
\hline $25-34$ & 97 & 23.7 \\
\hline $35-44$ & 102 & 24.9 \\
\hline$\geq 45$ & 175 & 42.6 \\
\hline \multicolumn{3}{|l|}{ Residence } \\
\hline Urban & 202 & 49.3 \\
\hline Rural & 208 & 50.7 \\
\hline \multicolumn{3}{|l|}{ Level of education } \\
\hline Informal education & 212 & 51.7 \\
\hline Formal educated & 198 & 48.3 \\
\hline \multicolumn{3}{|l|}{ Marital Status } \\
\hline Married & 295 & 72.0 \\
\hline Single & 115 & 28.0 \\
\hline \multicolumn{3}{|l|}{ Family size } \\
\hline $\mathrm{I}-5$ & 323 & 78.8 \\
\hline 6 and above & 87 & 21.2 \\
\hline \multicolumn{3}{|l|}{ Religion } \\
\hline Orthodox & 349 & 85.1 \\
\hline Protestant & 42 & 10.3 \\
\hline Wakefata & 3 & 0.7 \\
\hline Muslim & 16 & 3.9 \\
\hline \multicolumn{3}{|l|}{ Ethnicity } \\
\hline Oromo & 357 & 87.1 \\
\hline Amhara & 43 & 10.5 \\
\hline Tigre & 2 & 0.5 \\
\hline Gurage & 8 & 1.9 \\
\hline \multicolumn{3}{|l|}{ Occupational status } \\
\hline Unemployed & 270 & 65.85 \\
\hline Employed & 140 & 34.15 \\
\hline \multicolumn{3}{|c|}{ Family monthly income (in } \\
\hline \multicolumn{3}{|c|}{ Birr) } \\
\hline$\leq 2000$ & 268 & 65.4 \\
\hline $200 I-5000$ & 104 & 25.4 \\
\hline $500 I-8000$ & 38 & 9.2 \\
\hline
\end{tabular}

market frequency. One hundred ninety-four participants were prepared isolation room for the COVID-19 suspected person (Table 3).

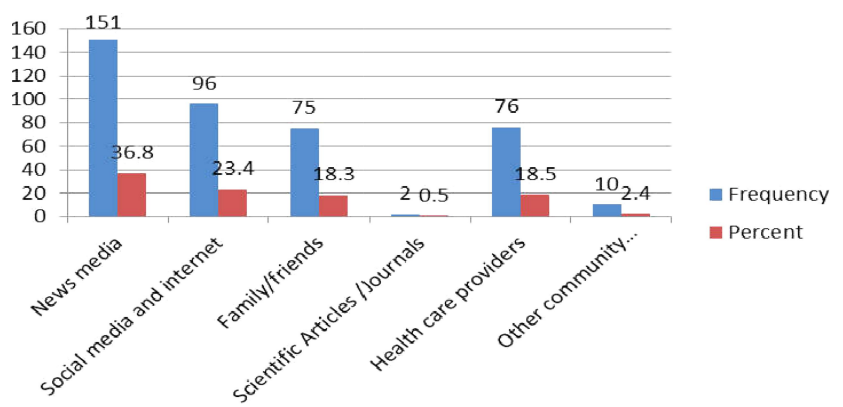

Figure 2 The COVID-19 source of information for the first time among chronic disease patients who had follow-up in the North Shoa Zone healthcare facilities, Oromia region, Ethiopia from May 5, 2020, to June 5/2020 ( $n=410)$.

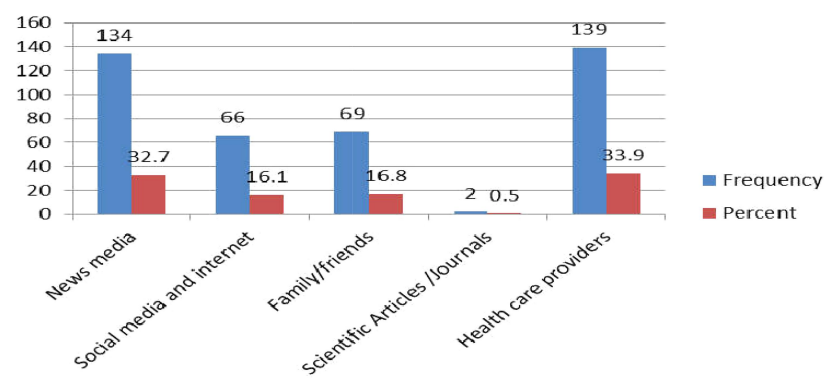

Figure 3 The trusted source of information among chronic disease patients who had follow-up in the North Shoa Zone healthcare facilities, Oromia region, Ethiopia, from May 5, 2020, to June 5/2020 $(n=410)$.

\section{Response to the COVID-19 Prevention}

In this cross-sectional study, we found the mean score and standard deviation of the study participants for the response to the COVID-19 prevention were $11.69 \pm 3.10$. From the total study participants, $62 \%$ of the respondents had a good response to COVID-19 prevention. The majority of the participants practice the COVID19 prevention by staying home (72.9\%), avoiding outdoor food consumption (72.9\%), avoiding handshaking $(89.5 \%)$, and avoiding public transportation (75.6\%). One-third of the participants used traditional medicine and vitamins to prevent COVID-19. Three hundred thirty-three of the participants wore masks, and $74 \%$ of the respondents used alcohol or sanitizer to prevent the disease. The majority of respondents were promoting preventive practice by teaching their family $(82 \%)$, a friend $(82.9 \%)$, and neighbors $(76.1 \%)$. Around $67 \%$ of the participants were posted hand washing procedures at home. Three hundred twenty-nine of the study participants also show the method to wear masks, hand rubbing, and hand washing procedures to their families (Table 4). 
Table 2 Knowledge of COVID-19 Among Chronic Disease Patients Who Had Follow-Up in the North Shaw Zone Healthcare Facilities, Oromia Region, from May 5, 2020, to June 5/2020 ( $n=410)$

\begin{tabular}{|c|c|c|}
\hline Knowledge Variables & Yes (\%) & No (\%) \\
\hline Do you heard about COVID-19? & $395(96.4 \%)$ & $15(3.6 \%)$ \\
\hline Does the COVID-19 is transmitted from one person to another? & $368(89.8)$ & $42(10.2)$ \\
\hline Does the COVID-19 have a treatment? & $206(50.2)$ & 204(49.8) \\
\hline Washing hands with water and soap can eliminate the COVID-19. & $354(86.4)$ & $56(13.6)$ \\
\hline Rubbing hands with alcohol or sanitizer eliminate COVID-19? & $328(80.0)$ & $82(20)$ \\
\hline Wearing a mask and glove reduce transmission of COVID-19? & $366(89.3)$ & $44(10.7)$ \\
\hline $\begin{array}{l}\text { The disease can be transmitted directly through contact with infected individuals (handshaking, hugging, } \\
\text { kissing) }\end{array}$ & $356(86.8)$ & $54(13.2)$ \\
\hline Do you think people with chronic disease at risk for COVID-19? & $323(78.8)$ & $87(21.2)$ \\
\hline Do you think the elder person's higher risk to get the COVID-19? & $310(75.6)$ & $100(24.4)$ \\
\hline Do you know maintaining a physical distance prevents COVID-19? & $354(86.3)$ & $56(13.7)$ \\
\hline $\begin{array}{l}\text { Do you know COVID-19 is prevented by social distance/limiting participation on Idir, Ikub, wedding, funeral, } \\
\text { and senbete? }\end{array}$ & $350(85.4)$ & $60(14.6)$ \\
\hline What are the main symptoms of COVID-19? Select from the following? & & \\
\hline Fever & $348(84.9)$ & $62(15.1)$ \\
\hline Cough/Sneeze & $337(82.2)$ & $73(17.8)$ \\
\hline Shortness of breath and breathing difficulties & $204(49.8)$ & $206(50.2)$ \\
\hline Sore throat & $134(32.7)$ & $276(67.3)$ \\
\hline Muscle pain & $94(22.9)$ & $316(77.1)$ \\
\hline Headache & $139(33.9)$ & $217(66.1)$ \\
\hline Minimum-Maximum & $0-17$ & \\
\hline Main $\pm S D$ & $12.11 \pm 2.7$ & \\
\hline Knowledgeably & $267(65.1 \%)$ & \\
\hline Not knowledgeably & $143(34.9 \%)$ & \\
\hline
\end{tabular}

Table 3 Preparedness Toward COVID-19 Prevention of Chronic Diseases Patients Who Had Follow-Up in the North Shaw Zone Healthcare Facilities, Oromia Region, from May 5, 2020, to June 5/2020 ( $=410)$

\begin{tabular}{|c|c|c|}
\hline Preparedness Variables & Yes (\%) & No (\%) \\
\hline Do you have water and soap at your house get to prevent COVID-19? & $328(80)$ & $82(20)$ \\
\hline Do you stock alcohol or sanitizer to prevent COVID-19? & 299(72.9) & $\mathrm{III}(27 . \mathrm{I})$ \\
\hline Do you stock mask and glove to prevent COVID-19? & $95(23.2)$ & $315(76.8)$ \\
\hline Do you stock sufficient medication for your chronic illness? & $26 I(63.7)$ & $149(36.3)$ \\
\hline Do you have an emergency phone number in a visible area in the house? & $145(35.4)$ & 265(64.6) \\
\hline Do you stock blench to prevent COVID-I9? & $188(45.9)$ & $222(54.1)$ \\
\hline Do you stock dustbin for soft tissue disposal? & $238(58)$ & $172(42.0)$ \\
\hline Will your family allow time to prepare and preventive measures? & $269(65.6)$ & $|4|(34.4)$ \\
\hline Do you reduce the frequency of visiting the hospital during COVID-19? & $265(64.6)$ & $145(35.4)$ \\
\hline Do you stock sufficient food to reduce frequency marketing? & $217(52.9)$ & 193(47.1) \\
\hline Do you prepare an isolation room for suspected family members? & 194(47.3) & $216(52.7)$ \\
\hline Minimum - maximum & \multirow{2}{*}{\multicolumn{2}{|c|}{$\begin{array}{l}0-11 \\
6.63 \pm 2.9\end{array}$}} \\
\hline Mean \pm SD & & \\
\hline \multicolumn{3}{|l|}{ COVID-19 prevention, preparedness } \\
\hline Good preparedness & \multicolumn{2}{|l|}{$219(53.4)$} \\
\hline poor preparedness & \multicolumn{2}{|l|}{$191(46.6)$} \\
\hline
\end{tabular}


Table 4 Response Against the COVID-19 Prevention Among Chronic Disease Patients Who Had Follow-Up in the North Shaw Zone Healthcare Facilities, Oromia Region, from May 5, 2020, to June 5/2020 ( $n=410)$

\begin{tabular}{|c|c|c|}
\hline Response Variables & Yes (\%) & No (\%) \\
\hline Do you avoid going out of your home to prevent the COVID-19? & $299(72.9 \%)$ & III(27.I\%) \\
\hline Do you avoid consuming outdoor food to prevent contracting COVID-19? & $300(73.2 \%)$ & $110(26.8 \%)$ \\
\hline Do you avoid handshaking, hugging, and Kissing to avoid the COVID-19? & $367(89.5 \%)$ & $43(10.5 \%)$ \\
\hline Do you avoid using public transportations to avoid contacting COVID-19? & $310(75.6 \%)$ & $100(24.4 \%)$ \\
\hline To prevent COVID-19, Do you frequently wash your hands with soap? & $357(87.1 \%)$ & $53(12.9 \%)$ \\
\hline Do you pay more attention to your hygiene than usual to prevent COVID-I9? & $334(81.5 \%)$ & $76(18.5 \%)$ \\
\hline Do you use herbal products and traditional medicine to prevent COVID-19? & $163(39.8 \%)$ & $247(60.2 \%)$ \\
\hline To prevent COVID-19, do you take a vitamin or immunity boost supplements? & $161(39.3 \%)$ & $249(60.7 \%)$ \\
\hline Do you start using masks to prevent COVID-19? & $338(82.4 \%)$ & $72(17.6 \%)$ \\
\hline To prevent COVID-19, do you use disinfectant solutions/alcohol/sanitizer? & $302(73.7 \%)$ & $108(26.3 \%)$ \\
\hline To prevent the COVID-19, do you avoid unnecessary vacations? & $272(66.3 \%)$ & $138(33.7 \%)$ \\
\hline Do you teach about COVID-19 prevention methods for your family members? & $336(82 \%)$ & $74(18 \%)$ \\
\hline Do you teach about COVID-19 prevention methods for your friends? & $340(82.9 \%)$ & $70(17.1 \%)$ \\
\hline Do you teach about COVID-19 prevention methods for your neighborhood? & $312(76.1 \%)$ & $98(23.9 \%)$ \\
\hline Do you post a hand washing procedure in your house for your family members? & $274(66.8 \%)$ & $136(33.2 \%)$ \\
\hline Do you show hand washing/mask/glove using procedures for your family? & $329(80.2 \%)$ & $81(19.8 \%)$ \\
\hline Minimum-Maximum & \multicolumn{2}{|l|}{$0-16$} \\
\hline Mean \pm SD & \multicolumn{2}{|l|}{$11.69 \pm 3.10$} \\
\hline \multicolumn{3}{|l|}{ Response against COVID-19 prevention } \\
\hline Good response & \multicolumn{2}{|l|}{$256(62.4 \%)$} \\
\hline Poor response & \multicolumn{2}{|l|}{$154(37.6 \%)$} \\
\hline
\end{tabular}

\section{Factors Associated with Preparedness and Response to the COVID-I9 \\ Pandemic}

Bivariable and multivariable logistic regression was computed. Variables with $\mathrm{P}$-value $<0.2$ in the bivariable analysis were entered into multivariable logistic analysis to predict factors associated with a good preparedness and responses at a p-value of less than 0.05 .

Accordingly, male participants had 1.05 times more likely prepared than female participants $[\mathrm{AOR}=1.05$; $95 \% \mathrm{CI}=(1.01,2.33)]$. The study participants who have followed the news media (TV \& Radio) had two times more likely prepared when compared to those who were informed by health-care providers $[\mathrm{AOR}=2.16 ; 95 \% \mathrm{CI}=$ $(1.35,4.02)]$. The study participants who follow social media had higher odds of preparedness than their counterparts $[\mathrm{AOR}=3.09 ; 95 \% \mathrm{CI}=(1.90,6.63)]$. Study participants who had a chronic disease like tuberculosis $[\mathrm{AOR}=2.22 ; \quad 95 \% \quad \mathrm{CI}=(1.66,3.24)]$, hypertension $[\mathrm{AOR}=1.49,95 \% \mathrm{CI}=(1.79,2.78)]$ and diabetes mellitus $[\mathrm{AOR}=1.62 ; 95 \% \mathrm{CI}=(1.82,3.19)]$ had also higher odds of having good preparedness of the COVID-19 prevention than their counterparts (Table 5).
Participants who have informal education were responded to the COVID-19 pandemic by $49 \%$ higher than those with formal education $[\mathrm{AOR}=0.49 ; 95 \% \mathrm{CI}=$ $(0.30,0.91)]$. Those study participants who had to follow the news media (TV \& Radio) had three timed more likely respond to the COVID-19 pandemic than those who had informed from the health-care providers $[\mathrm{AOR}=2.719 ; 5 \% \mathrm{CI}=(1.47,4.07)]$. Those participants who have hypertension were 2.07 times more likely to respond to the COVID-19 prevention compared to the other chronic disease patients $[\mathrm{AOR}=2.07 ; 95 \% \mathrm{CI}=$ $(1.14,4.02)]$ (Table 6).

\section{Discussion}

The COVID-19 is an emerging infectious disease that poses a significant threat to public health, especially for chronic disease patients. We found that $65 \%$ of the study participants knowledgeable about COVID-19. This proportion is less than the studies conducted in Arbaminch Ethiopia, ${ }^{15}$ resident of Ethiopia, ${ }^{16}$ the Kingdom of Saudi Arabia, ${ }^{17}$ Iran, ${ }^{13}$ China,${ }^{18}$ Nepal, ${ }^{14}$ and Egypt. ${ }^{19}$ The possible explanation for the difference could be due to a difference in educational level, social, cultural, economic, and personal characteristics 
Table 5 Factors Associated with Preparedness Towards COVID-I9 Prevention in North Shaw Zone Healthcare Facilities, Oromia Region, from May 5, 2020, to June 5/2020 ( $n=410)$

\begin{tabular}{|c|c|c|c|c|}
\hline \multirow[t]{2}{*}{ Variables } & \multicolumn{2}{|c|}{ Preparedness } & \multirow[t]{2}{*}{$\operatorname{COR}(95 \% \mathrm{Cl})$} & \multirow[t]{2}{*}{ AOR(95\% Cl) } \\
\hline & No & Yes & & \\
\hline \multicolumn{5}{|l|}{ Age } \\
\hline $15-24$ & 12 & 24 & I & I \\
\hline $25-34$ & 46 & 51 & $0.55(0.25,1.23)$ & $0.33(0.20, \mathrm{I} . \mathrm{II})$ \\
\hline $35-44$ & 52 & 50 & $0.48(0.22,1.66)$ & $0.29(0.20,1.50)$ \\
\hline$\geq 45$ & 81 & 94 & $0.58(0.27,1.65)$ & $0.42(0.21,1.50)$ \\
\hline \multicolumn{5}{|l|}{ Sex } \\
\hline Male & 89 & 126 & $1.55(1.05,2.30)^{*}$ & $1.05(1.01,2.33)^{*}$ \\
\hline Female & 102 & 93 & I & I \\
\hline \multicolumn{5}{|l|}{ Residence } \\
\hline Urban & 93 & 109 & $\mathrm{I}$ & 1 \\
\hline Rural & 98 & 208 & $1.04(0.7|-| .54)$ & $0.95(0.97,1.26)$ \\
\hline \multicolumn{5}{|l|}{ Level of education } \\
\hline Informal education & 105 & 107 & $0.78(0.53,1.16)$ & $0.65(0.46,1.10)$ \\
\hline Formal education & 86 & 112 & I & I \\
\hline \multicolumn{5}{|l|}{ Marital Status } \\
\hline Married & 142 & 153 & I & I \\
\hline Single & 49 & 66 & $0.80(0.52,1.24)$ & $0.56(0.391,1.19)$ \\
\hline \multicolumn{5}{|l|}{ Occupational status } \\
\hline Unemployed & 128 & 142 & $0.91(0.60,1.37)$ & $0.85(0.57,1.24$ \\
\hline Employed & 63 & 77 & 1 & I \\
\hline \multicolumn{5}{|l|}{ Family monthly income (in Birr) } \\
\hline$\leq 2000$ & 124 & 144 & $0.99(0.50,1.97)$ & $0.73(0.44, I .43)$ \\
\hline $200 I-5000$ & 50 & 54 & $0.92(0.43,1.95)$ & $0.56(0.41,1.68)$ \\
\hline $500 \mathrm{I}-8000$ & 17 & 20 & I & 1 \\
\hline \multicolumn{5}{|l|}{ Family size } \\
\hline $\mathrm{I}-5$ & 148 & 175 & I & 1 \\
\hline 6 and above & 43 & 44 & I.I3(0.70,I.82) & $1.08(0.63,1.83)$ \\
\hline \multicolumn{5}{|l|}{ Knowledge } \\
\hline Poor knowledge & 106 & 128 & $1.13(0.76,1.67)$ & $1.09(0.71,1.66)$ \\
\hline Good knowledge & 85 & 91 & I & 1 \\
\hline \multicolumn{5}{|l|}{ Source of information } \\
\hline News media & 61 & 90 & $2.58(1.50,4.44)^{*}$ & $2.16(1.35,4.02)^{*}$ \\
\hline Social media and internet & 33 & 63 & $3.34(1.82,6.12)^{*}$ & $3.09\left(1.90,6.63^{*}\right.$ \\
\hline Family/friends & 41 & 34 & $1.45(0.77,2.72)$ & I.I5(0.50,2.07) \\
\hline Health care providers & 56 & 32 & 1 & 1 \\
\hline \multicolumn{5}{|l|}{ Types of Chronic disease } \\
\hline HIVIADIS & 66 & 73 & I & I \\
\hline TB & 32 & 40 & $2.53(1.99,6.53)^{*}$ & $2.22(1.66,3.24)^{*}$ \\
\hline Hypertension & 32 & 44 & $2.86(1.05,7.79)^{*}$ & $1.49(1.79,2.78)^{*}$ \\
\hline Diabetes mellitus & 21 & 39 & $3.14(1.16,8.53)^{*}$ & $1.62(1.82,3.19)^{*}$ \\
\hline Heart failure & 18 & 15 & $4.25(1.51,11.94)^{*}$ & $1.05(0.46,2.39)$ \\
\hline Cancer & 6 & 1 & I.9I $(0.62,5.85)$ & $0.17(0.02, I .5 \mathrm{I})$ \\
\hline Others & 16 & 7 & $0.38(0.04,3.78)$ & $0.36(0.13,1.02)$ \\
\hline
\end{tabular}

Notes: $I=$ reference, and $*=$ statistically significant at $p$-value $<0.05$ in bivariable and multivariable logistic regression, Hosmer and Lemeshow test $=0.935$. 
Table 6 Factors Associated with Response to COVID-19 Prevention in North Shaw Zone Healthcare Facilities, Oromia Region, from May 5, 2020, to June 5/2020 (n=4l0)

\begin{tabular}{|c|c|c|c|c|}
\hline \multirow[t]{2}{*}{ Variables } & \multicolumn{2}{|c|}{ Response } & \multirow[t]{2}{*}{ COR(95\% Cl) } & \multirow[t]{2}{*}{ AOR(95\% Cl) } \\
\hline & No & Yes & & \\
\hline \multicolumn{5}{|l|}{ Age } \\
\hline $15-24$ & 12 & 24 & 1 & 1 \\
\hline $25-34$ & 39 & 58 & $0.74(0.33,1.66)$ & $0 .(35(0.23,1.56)$ \\
\hline $35-44$ & 41 & $6 I$ & $0.70(0.30,1.64)$ & $0.65(0.28,1.60)$ \\
\hline$\geq 45$ & 62 & 113 & $0.91(0.43,1.95)$ & $0.85(0.4 I, I .86)$ \\
\hline \multicolumn{5}{|l|}{ Sex } \\
\hline Male & 73 & 142 & $1.38(0.93,2.06)$ & $1.32(0.90,1.99)$ \\
\hline Female & 81 & 114 & 1 & 1 \\
\hline \multicolumn{5}{|l|}{ Residence } \\
\hline Urban & 68 & 134 & 1 & I \\
\hline Rural & 86 & 122 & $0.72(0.48,1.98)$ & $0.56(0.39,1.60)$ \\
\hline \multicolumn{5}{|l|}{ Level of education } \\
\hline Informal education & 95 & 117 & $0.52(0.35,0.79)^{*}$ & $0.49(0.30,0.91)^{*}$ \\
\hline Formal education & 59 & 139 & 1 & 1 \\
\hline \multicolumn{5}{|l|}{ Marital Status } \\
\hline Married & 114 & 181 & I & 1 \\
\hline Single & 40 & 75 & I.I8(0.75, I.85) & $1.08(0.71,1.67)$ \\
\hline \multicolumn{5}{|l|}{ Occupational status } \\
\hline unemployed & 110 & 160 & $0.67(0.43,1.63)$ & $0.5 \mathrm{I}(0.4 \mathrm{I}, \mathrm{I} .03)$ \\
\hline employed & 44 & 96 & 1 & 1 \\
\hline \multicolumn{5}{|l|}{ Family monthly income (in Birr) } \\
\hline$\leq 2000$ & 98 & 170 & $0.83(0.40, I .73)$ & $0.79(0.26, I .6 I)$ \\
\hline $200 I-5000$ & 44 & 60 & $0.66(0.30, I .44)$ & $0.57(0.23, I .40)$ \\
\hline $500 \mathrm{I}-8000$ & 12 & 25 & 1 & 1 \\
\hline \multicolumn{5}{|l|}{ Family size } \\
\hline $1-5$ & 114 & 209 & 1 & 1 \\
\hline 6 and above & 40 & 47 & $0.64(0.40, I .44)$ & $0.55(0.37,1.14)$ \\
\hline \multicolumn{5}{|l|}{ Knowledge } \\
\hline Poor knowledge & 85 & 149 & $\mathrm{I} .13(0.76, \mathrm{I} .67)$ & I.I I $(0.7 I, I .64)$ \\
\hline Good knowledge & 69 & 107 & 1 & 1 \\
\hline \multicolumn{5}{|l|}{ Source of information } \\
\hline News media & 40 & 111 & $2.76(I .60,4.820 *$ & $2.71(1.47,4.07)^{*}$ \\
\hline Social media and internet & 37 & 59 & $1.60(0.89,2.87)^{*}$ & $\mathrm{I} .24(0.63,2.43)$ \\
\hline Family/friends & 33 & 42 & $1.27(0.69,2.36)$ & $1.05(0.60,2.08)$ \\
\hline Health care providers & 44 & 44 & 1 & I \\
\hline
\end{tabular}

Notes: $\mathrm{I}=$ reference, and $*=$ statistically significant at $\mathrm{p}$-value $<0.05$ in bivariable and multivariable logistic regression, Hosmer and Lemeshow test $=0.786$.

of the study participants. On the other hand, the finding is higher than the studies conducted in Jimma University medical center visitors ${ }^{20}$ and Addis Zemen District Hospital. ${ }^{21}$ This discrepancy may be due to the differences in a tool used to assess the respondents' knowledge.
In this study, we found that $78.8 \%$ of the respondents knew chronic disease patients have a high susceptibility to the COVID-19 pandemic. This result was lower than the studies conducted in Jimma University medical center visitors, ${ }^{20}$ Kingdom of Saudi Arabia, ${ }^{17}$ Malaysia, ${ }^{22}$ and 
Germany. ${ }^{23}$ The possible justification for the difference could be due to a difference in study participants' socioeconomic status. Conversely, this finding is higher than the study reported in Addis Zemen District Hospital, Ethiopia. ${ }^{21}$ The finding difference may be due to the time of data collection.

This study found that most participants had accessed information from new media (TV and radio). This finding is in line with the studies conducted in Addis Zemen District Hospital, ${ }^{21}$ Arbaminch Ethiopia, ${ }^{15}$ and Egypt. ${ }^{19}$ The possible explanation for the similarity is that most participants need easy and accessible ways of getting information. Most of the community used easily accessible media like TV and radio to obtained information about the COVID-19 pandemic. On the other hand, this result is different from studies conducted in Iran, ${ }^{13}$ United Arab Emirates, ${ }^{24}$ and Nigeria, ${ }^{25}$ and Egypt. ${ }^{19}$ This difference may be due to the study participants' educational level, social, cultural, economic, and personal characteristics.

This study revealed that $53.4 \%$ of the study respondents were well prepared to prevent the COVID-19 pandemic. Their preparedness methods to the COVID-19 included sufficient stocking amounts of food items, alcohol/sanitizer, preparing isolation rooms for suspected family members, posted an emergency phone number at home, and refilled their medication for three months. This is a significant contribution for declared an emergency and mandated compulsory physical distancing, stay at home, frequent hand washing, and wear the masks to control the COVID-19 pandemic spread, recommended by WHO. ${ }^{26}$ This preparedness to the COVID-19 is not a fixed rule; it may be changed by advancing knowledge of chronic disease patients, coping mechanisms for prevention, and controlling the COVID-19 pandemic.

Our study found that $62.4 \%$ of respondents had a good response to COVID-19 prevention. This finding is less than the studies reported in Iran, ${ }^{13}$ and China. ${ }^{18}$ The possible justification of this inconsistency may be due to differences in information-seeking behavior, frequency of media exposure, education status, and the study participant's anxiety related to the pandemic, which leads to the variation in the application of recommended precaution and early response to the COVID-19. The other possible difference maybe a total lock down and travel restrictions implemented by China and Iran to control the COVID-19 pandemic transmission. In opposition, this finding is higher than the study conducted in Addis Zemen District Hospital, Ethiopia. ${ }^{21}$ This discrepancy may be due to the time of data collection and tools used.
When each of the specific components of preventive practice was analyzed, our study finding indicated that $89.5 \%$ of participants avoiding handshaking and kissing to prevent COVID-19. This finding was higher than the studies conducted in Jimma, Ethiopia, ${ }^{20}$ Addis Zemen District Hospital, Ethiopia, ${ }^{21}$ and the Kingdom of Saudi Arabia. ${ }^{16}$ This inconsistency is may be due to differences in data collection times and tools. Eighty-seven percent of the participants practice hand washing to prevent COVID-19, which was higher than the studies reported in Arbaminch, ${ }^{15}$ Jimma $^{20}$ and Addis Zemen District Hospital, Ethiopia. ${ }^{21}$ This difference may be due to the time of data collection and difference in study participants. Again, this result is lower than the studies result reported in Nepal, ${ }^{14}$ and Malaysia. ${ }^{22}$ This difference is explained by modest coverage and intermittent water supply in our study facilities.

In this study, we found that $82.4 \%$ of participants wearing a mask to prevent COVID-19, which in line with the study reported in Arbaminch Ethiopia, ${ }^{15}$ and higher than the studies reported in Addis Zemen District Hospital, $^{21}$ Paraguay, ${ }^{27}$ and Malaysia. ${ }^{22}$ The discrepancy might be occurred due to the data collection period. Conversely, this finding is lower than the studies conducted in Bangladesh, ${ }^{28}$ Nepal $^{14}$ and Chinas residents. ${ }^{18}$ This lower practice of wearing a mask in Ethiopia might be due to the inability to afford and lack of strict follow-up with the local government to enforcing the policies to wear a mask.

Our study found male participants were significantly associated with good prepared to prevent the COVID-19 pandemic. This contradicted the study reported in the Kingdom of Saudi Arabia, which revealed that women were more practiced in preventing the COVID-19. ${ }^{16}$ The possible justification for this finding; the male population was more at risk to COVID-19 than the female due to their daily work was out of the door. As a result, the male's chronic disease patients were more prepared and response to the COVID-19 pandemic than female participants. Again, our findings revealed that participants with informal education had significantly higher good responses to the COVID-19 pandemic. This explained by chronic disease patients who had follow-up at the healthcare facilities regularly may have updated information on the COVID-19 prevention methods from the healthcare professionals.

Different studies indicated that chronic disease patients have a high risk of morbidity and mortality from COVID19 infections. ${ }^{10,12}$ This study found that participants who 
have chronic hypertension, tuberculosis, diabetes have higher response and preparedness of COVID-19 prevention. This similar to the study result reported in China that revealed chronic hypertension disease, respiratory system disease, hypertension, and cardiovascular diseases were more connected with the COVID-19 prevention and response. $^{29}$ Patients may have higher preparedness and response to the COVID-19 infection prevention and control as recognizing their chronic disease.

We found that participants who had followed the news media (TV \& Radio) and social media had higher preparedness and response to prevent the COVID-19 pandemic. This was in line with the study done in Arbaminch, Ethiopia. ${ }^{14}$ In fact, social media, TV, and radio are instruments that promoted the prevention of the COVID-19 infection by demonstrating frequent hand hygiene and self-care, avoiding social gatherings (maintaining social distancing). This is a good opportunity that should be encouraged and continued to provide the current pandemic prevention and control method.

\section{Limitation of the Study}

This study has limited to the North Shoa Zone, and respondents might give socially acceptable answers, which may have desirable Social bias. The tool used to assess knowledge, preparedness, and responses were not standardized. The discussion part did not compare with other literature due to the limited number of published articles during this study conducted.

\section{Conclusion}

We found that the level of knowledge, preparedness, and response to the COVID-19 among chronic disease patients was low. Male participants, source of information, educational status, and having chronic disease ware significantly associated with the COVID-19 preparedness and response. Therefore, to increase knowledge, preparedness, and response to the COVID-19 among chronic disease patients needs coordinated effort from the health professional, government, and nongovernment organization. The government should be continuing awareness creation on COVID-19 prevention and control methods through news media (TV and Radio) and social media by collaboration with a health professional. Effective prevention and control of the COVID-19 are achieved through increasing the populations' knowledge and practices towards COVID-19. A health professional who works at a health facility or chronic outpatient department should be provided information about the COVID-19 pandemic for the chronic disease patients during their follow-up period and refill sufficient medication for three months to reduce the frequency of visiting the healthcare facilities.

\section{Abbreviations}

CDC, Center for Disease Control and Prevention; CFR, curd fatality rate; COVID-19, Corona Virus Disease 2019; MERS, Middle East Respiratory Syndrome; NCD, noncommunicable disease; SARS, severe acute respiratory syndrome; WHO, World Health Organization.

\section{Data Sharing Statement}

The datasets used and analyzed during the current study are available from the corresponding author on a reasonable request.

\section{Ethics Approval and Informed Consent}

This study was conducted in accordance with the Declaration of Helsinki. The Salale University Ethical Review Committee were approved the ethical clearance of written consent for above 18 years of age and assent form for under 18 years of age from parents/guardians on April 27/2020 with Ref. No. SLUERC/035/2020. A support letter was obtained from the North Showa Zone health bureau, and official permission was obtained from the selected hospitals and health centers. Written consent was obtained from the study participants whose age $\geq 18$ years, and assent was obtained from parents/guardians for 15 to 18 years old to confirm the participation after explaining the study's objective. Study participants' privacy and confidentiality were maintained by excluding their names from the questionnaire and keeping their data in a password locked computer.

\section{Acknowledgments}

The authors acknowledge the Salale University, all health facilities from where the data were collected, and study participants for their cooperation.

\section{Author Contributions}

All authors made a significant contribution to the conception, study design, execution, and acquisition of data, analysis, and interpretation. All authors involved in drafting, revising, or critically reviewing the article; gave final approval of the version to be published; have agreed on the journal to which the article has been submitted; and agree 
to be accountable for all aspects of the work. First Author: Tinsae Abeya Geleta.

\section{Funding}

The Salale University funds this research work. The funders had no role in study design, data collection, analysis, decision to publish, or manuscript preparation.

\section{Disclosure}

The authors declare that they have no competing interests.

\section{References}

1. Lu R, Zhao X, Li J, et al. Genomic characterisation and epidemiology of 2019 novel coronavirus: implications for virus origins and receptor binding. Lancet. 2020;395(10224):565-574. doi:10.1016/S01406736(20)30251-8

2. Shereen MA, Khan S, Kazmi A, Bashir N, Siddique R. COVID-19 infection: origin, transmission, and characteristics of human coronaviruses. J Adv Res. 2020;24:91-98. doi:10.1016/j.jare.2020.03.005

3. WHO. Coronavirus Disease (Covid-19) Outbreak: Rights, Roles and Responsibilities of Health Workers, Including Key Considerations for Occupational Safety; 2019.

4. World Health Organization. Coronavirus disease (COVID-19) outbreak situation. Coronavirus Dis. COVID-19 Pandemic.https://www. who.int/emergencies/diseases/novel-coronavirus-2019. 2020.

5. World Health Organizetion. Report of the Who-China Joint Mission on Coronavirus Disease 2019 (Covid-19). Vol. 2019; 2020.

6. European Centre for Disease Prevention and Contro. European Center for Disease Prevention and Control. Coronavirus disease 2019 (COVID-19) pandemic: increased transmission in the EU/ EEA and the UK - seventh update. Eur Cent Dis Prev Control [Internet]. 2020. Available from: https://www.ecdc.europa.eu/sites/ default/files/documents/RRA-seventh-update-Outbreak-ofcoronavirus-disease-COVID-19.pdf.

7. Di Gennaro F, Pizzol D, Marotta C, et al. Coronavirus diseases (COVID-19) current status and future perspectives: a narrative review. Int $J$ Environ Res Public Health. 2020;17(8):2690. doi:10.3390/ ijerph17082690

8. World health Organization. Noncommunicable Diseases Country Profiles; 2018.

9. World Health Oorganization. Noncommunicable Diseases; 2018.

10. Salam R. Expanding the definition of noncommunicable disease. $J$ Social Health Diabetes. 2016;4(2):67-70. doi:10.4103/2321-0656.187990

11. Yang J, Zheng Y, Gou X, Pu K, Chen Z, Guo Q. Prevalence of comorbidities and its effects in patients infected with SARS- CoV-2: a systematic review and meta-analysis. International Journal of Infectious Diseases Prevalence of comorbidities and its effects in patients infected with SARS-CoV-2: a s. Int J Infect Dis. 2020;94:91-95.

12. Pal R, Bhadada SK. COVID-19 and noncommunicable diseases. Postgrad Med J. 2020;96(1137):429-430. doi:10.1136/postgradmedj-2020-137742

13. Erfani A, Shahriarirad R, Ranjbar K, Alireza Mirahmadizadeh MM Knowledge, Attitude and Practice toward the Novel Coronavirus (COVID-19) Outbreak: A Population-Based Survey in Iran. Kbsnews [Internet]. 2020; Available from: http://news.kbs.co.kr/ news/view.do? ncd $=4355861$.
14. Hussain A, Garima T, Singh BM, Ram R, Tripti RP. Knowledge, attitudes, and practices towards COVID-19 among Nepalese Residents: A quick online cross-sectional survey. Asian J Med Sci. 2020;11(3):6-11. doi:10.3126/ajms.v11i3.28485

15. Wogayehu B, Taye W, Chisha Y, Faraja K. Knowledge regarding 2019 novel coronavirus (2019-nCoV) infection among final year health science students at Arbaminch College of Health Sciences, Southern Ethiopia: a cross - sectional study. Res Sq. 2020.

16. Bekele D, Tolossa T, Tsegaye R, Teshome W. The knowledge and practice towards COVID-19 pandemic prevention among residents of Ethiopia. bioRxiv. 2020:154.

17. Al-Hanawi MK, Angawi K, Alshareef N, et al. Knowledge, Attitude and Practice Toward COVID-19 Among the Public in the Kingdom of Saudi Arabia: A Cross-Sectional Study. Front Public Heal. 2020;8. doi:10.3389/fpubh.2020.00217

18. Zhong BL, Luo W, Li HM, et al. Knowledge, attitudes, and practices towards COVID-19 among chinese residents during the rapid rise period of the COVID-19 outbreak: A quick online cross-sectional survey. Int J Biol Sci. 2020;16(10):1745-1752. doi:10.7150/ijbs.45221

19. Abdelhafiz AS, Mohammed Z, Ibrahim ME, et al. Knowledge, Perceptions, and Attitude of Egyptians Towards the Novel Coronavirus Disease (COVID-19). J Community Health. 2020;45 (5):881-890. doi:10.1007/s10900-020-00827-7

20. Kebede Y, Yitayih Y, Birhanu Z, Mekonen S, Ambelu A. Knowledge, perceptions and preventive practices towards COVID-19 early in the outbreak among Jimma university medical center visitors, Southwest Ethiopia. PLoS One. 2020;15(5):1-15. doi:10.1371/journal.pone.0233744

21. Akalu Y, Birhanu Ayelign MD. Knowledge, Attitude and Practice Towards COVID-19 Among Chronic Disease Patients at. dovepress. 2020:124

22. Azlan AA, Hamzah MR, Sern TJ, Ayub SH, Mohamad E. Public knowledge, attitudes and practices towards COVID-19: A cross-sectional study in Malaysia. PLoS One. 2020;15(5):1-15. doi:10.1371/journal.pone. 0233668

23. Zipprich HM, Teschner U, Witte OW, Schönenberg A, Knowledge PT, Attitudes P. Burden During the COVID-19 Pandemic in People with Parkinson's Disease in Germany. J Clin Med. 2020;9(6):1643. doi:10.3390/jcm9061643

24. Bhagavathula AS, Aldhaleei WA, Rahmani J, Mahabadi MA, Bandari DK. Knowledge and Perceptions of COVID-19 Among Health Care Workers: cross-Sectional Study. JMIR Public Heal Surveill. 2020;6(2):e19160. doi:10.2196/19160

25. Ibrahim A, Elnadi H, Ia O, Bolarinwa O, Ahmed Z, Okechukwu O. Knowledge attitude and perceptions towards the 2019 Coronavirus Pandemic A bi-national survey in Africa. Medrxiv [Internet]. 2020;1-28. Available from: http://medrxiv.org/cgi/content/short/ 2020.05.27.20113951.

26. World Health Organization. Mental Health and Psychosocial Considerations During the COVID-19 Outbreak, 18 March 2020. World Health Organization; 2020.

27. Carlos Miguel Rios-González. Knowledge, attitudes and practices towards COVID-19 in Paraguayans during outbreaks: a quick online survey. Psychol Appl to Work an Introd to Ind Organ Psychol Tenth Ed Paul. 2012;53(9):1689-1699.

28. Paul A. Knowledge Attitude and Practice Towards Novel Corona Virus among Bangladeshi People Implications for mitigation measures. Medrxiv [Internet]. 2020;1-30. Available from: http://medrxiv. org/cgi/content/short/2020.05.05.20091181.

29. Yang J, Zheng Y, Gou X, et al. Prevalence of comorbidities in the novel Wuhan coronavirus (COVID-19) infection: a systematic review and meta-analysis. Int $j$ Infect Dis. 2020;94:91-95. doi:10.1016/j. ijid.2020.03.017 


\section{Publish your work in this journal}

The International Journal of General Medicine is an international, peer-reviewed open-access journal that focuses on general and internal medicine, pathogenesis, epidemiology, diagnosis, monitoring and treatment protocols. The journal is characterized by the rapid reporting of reviews, original research and clinical studies across all disease areas. The manuscript management system is completely online and includes a very quick and fair peer-review system, which is all easy to use. Visit http://www.dovepress.com/ testimonials.php to read real quotes from published authors.

Submit your manuscript here: https://www.dovepress.com/international-journal-of-general-medicine-journal 